\title{
Research on simulation and test analysis of hydraulic transient process in Jinping II Hydropower Station
}

\author{
CAO Chun-jian ${ }^{1, a}$, FANG Jie ${ }^{1}$, CHEN Shun-yi ${ }^{1}$, HUANG Jing-qian ${ }^{1}$ \\ ${ }^{1}$ HydroChina Huadong Engineering Corporation, No.201 Gaojiao Road, Hangzhou City, Zhejiang Province, P.R. China
}

\begin{abstract}
The paper takes Jinping II Hydropower Station $(8 \times 600 \mathrm{MW})$ as an example, based on the internal mechanism and operating characteristics of the system, the complete simulation model of the superlong and large water diversion and power generation system has been completed finally.Besides, the method of parameter calibration and correction for the main elements of the system is proposed.By the simulation model, two typical hydraulic transient process test conditions are simulated, here the involved test conditions are as following: double load rejection and primary frequency regulation. At the same time, the calculated results are compared with the test results. The results show that the proposed simulation model can describe the dynamic response characteristic of the super-long and large water diversion and power generation system accurately.
\end{abstract}

\section{Introduction}

A hydraulic transition process is the process in which water flow is changed from one stable state to another by some disturbance [1]. When the hydropower station unit is normally started and shut down, the load is accidentally rejected, and the inlet valve is improperly opened and closed, the hydraulic transition process will occur in the water diversion and power generation system, which will lead to drastic changes in the pipeline pressure and flow rate, the water level of the surge chamber or the speed of the unit. Especially when the unit is in abnormal runaway or braking condition, the system will produce a large dynamic load, and cause the system to appear strong pressure pulsation, vibration and water hammer, which seriously affects the safe and stable operation of the power station[2].

With a total installed capacity of $4800 \mathrm{MW}$ and a single unit capacity of 600MW, JP II Hydropower Station takes advantage of the natural drop of a $150 \mathrm{~km}$ river bend in a certain river, passes through the about $16.67 \mathrm{~km}$ hydraulic tunnel and obtains about $310 \mathrm{~m}$ waterhead. The power station has four hydraulic units, each of which is arranged by one tunnel and two units. The water diversion system is composed of the power station water intake, inlet emergency gate, hydraulic tunnel, differential surge tank, penstock, tailrace outlet emergency gate and tailrace tunnel, etc. [3, 4]. As the total installed capacity, single unit capacity and flow of JP II Hydropower Station are large, and its super-long and large-diameter hydraulic tunnel, giant differential surge tank and large hydrogenerator units are characterized by extremely complex hydraulic conditions, it is one of the key technical problems restricting the construction of JP II Hydropower
Station to accurately evaluate the dynamic response characteristics of water diversion and power generation system under various hydraulic transition conditions[5,6].

Because it is very expensive to study the hydraulic transition process of water diversion and power generation system by physical test, and sometimes it cannot be simulated and realized due to the restriction of actual engineering conditions, as one of the important means to simulate the real physical system, digital simulation has become an indispensable tool in power system research, planning, operation and design due to its advantages of low cost and no restriction of external environment[7]. In view of this, this paper takes JP II Hydropower Station as the research object, and uses the user-defined modelling function provided by HYSIM software which is a simulation calculation software for complex system hydraulic transition process, to establish a complete hydraulic transition process simulation model for superlong and large water diversion and power generation system. By the simulation model, two typical hydraulic transient process test conditions are simulated and analysed, such as double load rejection and primary frequency regulation. In order to provide a reliable simulation platform for checking the extreme control conditions of super-long and large water diversion and power generation system and exploring the long-term stable operation mechanism of the system, the calculated results are compared with the measured results.

\footnotetext{
${ }^{a}$ Corresponding author: cao_cj2@ecidi.com
} 


\section{Hydraulic transition process simulat- ion model}

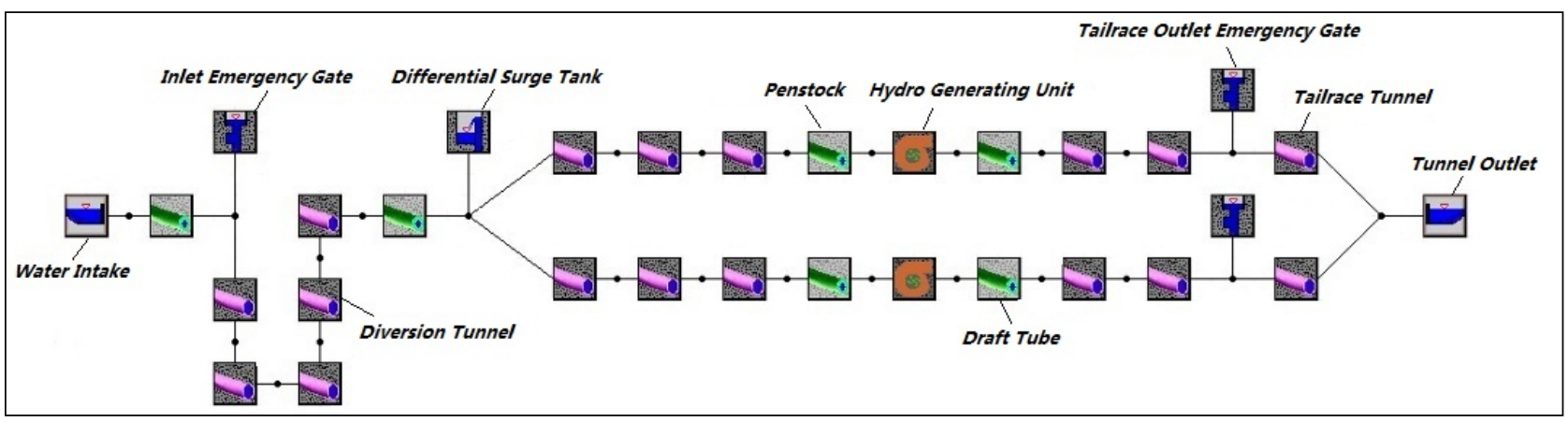

Figure 1. Simulation model of the super-long and large water diversion and power generation system by HYSIM

HYSIM, a simulation calculation software for complex system hydraulic transition process, was developed by Hydro China Huadong Engineering Corporation. The software has passed the evaluation of third-party software and has been successfully used in many large hydropower stations [8]. Under the simulation environment of HYSIM software, the simulation models of reservoir, elastic pipeline, differential surge tank, Francis turbine, microcomputer-governor, cylinder valve, hydro-generator and other main elements in JP II Hydropower Station are established by the user-defined modelling function of HYSIM software. Based on the internal mechanism and operating characteristics of JP II Hydropower Station, the complete simulation model of the super-long and large water diversion and power generation system has been completed finally, which is shown in Figure 1.

\section{Comparative analysis of test and simulation for double load rejection}

\subsection{Correction of the unit torque curve for the zero opening of Francis turbine}

After carrying out the load rejection test and simulation comparative study of JP II Hydropower Station, it is found that the measured speed and calculated speed of the unit are more consistent in the first half of the unit speed change curve, while they are quite different in the second half, which is mainly manifested in that the calculated speed is obviously lower than the measured speed. The reason shows that the guide vane opening in the second half of the unit speed change curve has been reduced to zero and it's in the Francis turbine braking area (the Francis turbine unit torque in this area is negative). When the calculated value of the Francis turbine unit torque at zero guide vane opening is less than the test value, the calculated speed of the unit will return to the stable state more quickly than the test speed. In view of this, it is necessary to properly correct the unit torque curve for the zero opening of Francis turbine in JP II Hydropower Station. The comparison between unit torque correction curve with non-correction curve for the zero opening of Francis turbine is shown in Figure 2.

Taking a single load rejection condition of JP II
Hydropower Station as an example, the comparison between the unit calculated speed of unit torque correction and non-correction curve for the zero opening with the unit test speed is shown in Figure 3.It can be seen from Figure 3 that the coincidence degree between the unit test speed with the unit calculated speed of the unit torque correction curve for the zero opening is obviously higher than the unit calculated speed of the unit torque noncorrection curve, which indicates that the unit torque correction curve for the zero opening of Francis turbine is suitable. In addition, it can be seen from Figure 3 that the maximum unit calculated speed of unit torque correction curve and non-correction curve is basically the same, which indicates that the unit torque curve for the zero opening of Francis turbine only has certain influence on the speed reduction rate of the unit, but has little influence on the maximum unit calculated speed.

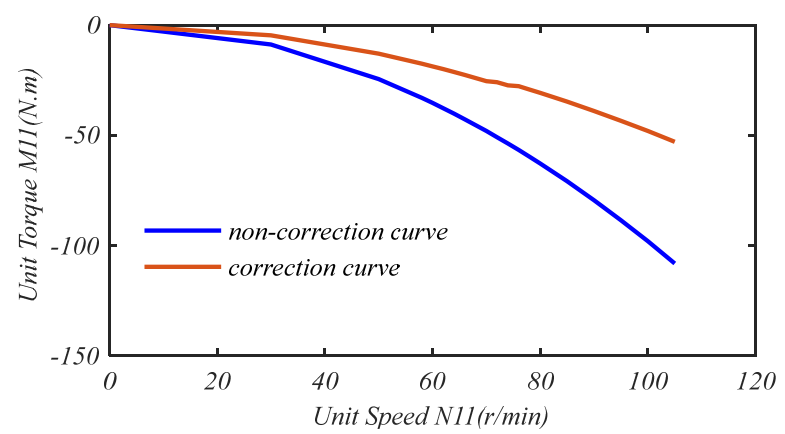

Figure 2. The comparison between unit torque correction curve with non-correction curve for the zero opening of Francis turbine

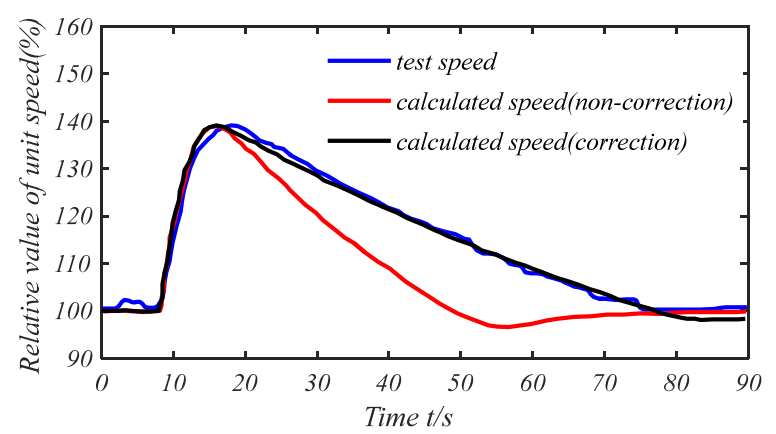

Figure 3. The comparison between the unit calculated speed of unit torque correction and non-correction curve for the zero opening with the unit test speed 


\subsection{Test conditions}

Due to the layout of one tunnel and two units in the water diversion and power generation system of JP II Hydropower Station, there is a situation that two units are running at full load and suddenly dropping the load. According to the requirements of relevant standards, the double load rejection test of JP II Hydropower Station should be completed before the unit is put into operation for power generation to verify whether the system parameters can meet the control requirements of regulating guarantee. The double load rejection test conditions of $7^{\#}$ and $8^{\#}$ units for JP II Hydropower Station are shown in Table 1.

Table 1. The double load rejection test conditions of JP II Hydropower Station

\begin{tabular}{|c|c|c|c|}
\hline $\begin{array}{c}\text { Test } \\
\text { conditions }\end{array}$ & $\begin{array}{c}\text { Upper } \\
\text { reservoir } \\
\text { water } \\
\text { level } \\
(\mathrm{m})\end{array}$ & $\begin{array}{c}\text { Lower } \\
\text { reservoir } \\
\text { water } \\
\text { level } \\
(\mathrm{m})\end{array}$ & \multicolumn{1}{c|}{$\begin{array}{c}\text { Description of test } \\
\text { conditions }\end{array}$} \\
\hline S1 & 1644.4 & 1328.01 & $\begin{array}{l}7^{\#} \text { and } 8^{\#} \text { units are running at } \\
\text { full rated load (600MW) and } \\
\text { both suddenly dropping the } \\
\text { load. The microcomputer- } \\
\text { governor closes the guide } \\
\text { vane by the setting law }\end{array}$ \\
\hline
\end{tabular}

\subsection{Analysis of simulation and test results}

According to $\mathrm{S} 1$ test condition, using the simulation model of the super-long and large water diversion and power generation system shown in Figure 1, the double load rejection simulation calculation of $7^{\#}$ and $8^{\#}$ units for JP II Hydropower Station is carried out. The comparison between the calculated values of regulating guarantee with the test values is shown in Table 2.Figure $4 \sim 6$ show the comparative curves of the unit speed, spiral case inlet pressure, draft tube inlet pressure of $7^{\#}$ unit under S1 test condition. Figure 7 shows the comparative curves of the water level for differential surge tank under S1 test condition.

It can be seen from Figures $4 \sim 7$ that the calculated curves of unit speed, spiral case inlet pressure, draft tube inlet pressure and water level of differential surge tank are basically consistent with the test curves, and the extremism occurrence time of regulating guarantee values is basically consistent. In addition, it can be seen from Table 2 that calculated values of the maximum unit relative speed for $7^{\#}$ and $8^{\#}$ unit are basically the same as the test values, and the relative values of maximum deviation are only $1.7 \%$ and $0.5 \%$ respectively. The calculated values of the maximum spiral case inlet pressure for $7^{\#}$ and $8^{\#}$ unit are very close to the test values, and the relative values of the maximum deviation are only $0.4 \%$ and $0.3 \%$ respectively. The calculated values of the minimum draft tube inlet pressure for $7^{\#}$ and $8^{\#}$ unit are slightly different from the test values, and the deviations between them are only $2.43 \mathrm{~m}$ and $3.27 \mathrm{~m}$ respectively. The calculated values of maximum and minimum water level for differential surge tank are basically close to the test values, and the deviations between them are only $2.99 \mathrm{~m}$ and $1.1 \mathrm{~m}$ respectively. In view of this, it can be seen that the simulation model of hydraulic transient process established in this paper can accurately reflect the dynamic response characteristics of double load rejection.

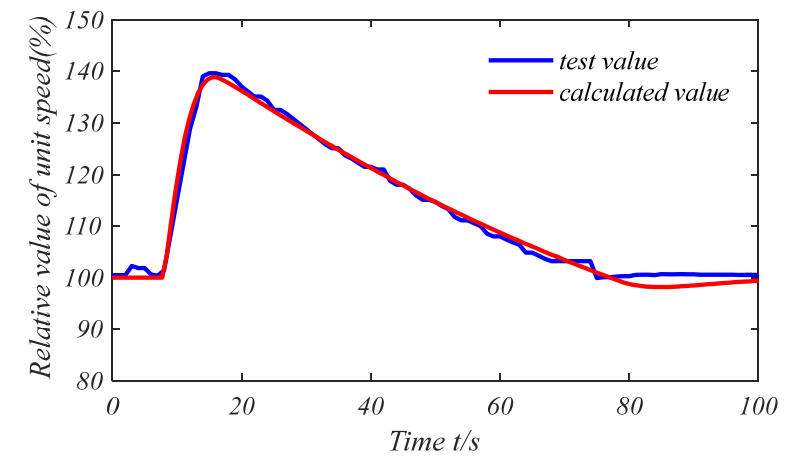

Figure 4. The comparative curves of $7^{\#}$ unit speed

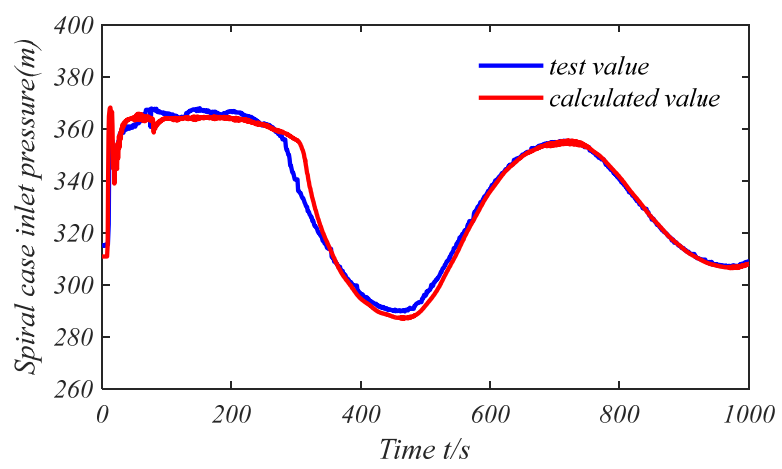

Figure 5. The comparative curves of $7^{\#}$ unit spiral case inlet pressure

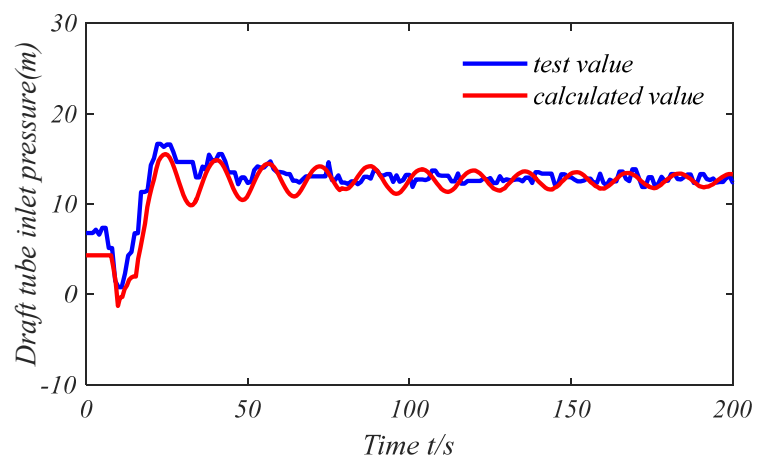

Figure 6. The comparative curves of $7^{\#}$ unit draft tube inlet pressure

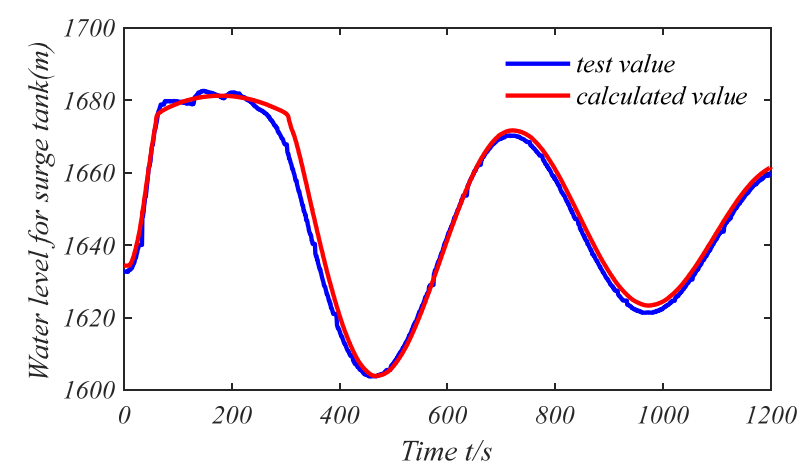

Figure 7. The comparative curves of the water level for differential surge tank 
Table 2. The calculated values and test values of regulating guarantee under S1 test condition

\begin{tabular}{|c|c|c|c|c|c|c|c|c|c|c|}
\hline \multirow[t]{2}{*}{ Unit } & \multicolumn{2}{|c|}{$\begin{array}{l}\text { Maximum unit } \\
\text { relative speed } \\
(\%)\end{array}$} & \multicolumn{2}{|c|}{$\begin{array}{l}\text { Maximum spiral case } \\
\text { inlet pressure } \\
(\mathrm{m})\end{array}$} & \multicolumn{2}{|c|}{$\begin{array}{l}\text { Minimum draft tube } \\
\text { inlet pressure } \\
(\mathrm{m})\end{array}$} & \multicolumn{2}{|c|}{$\begin{array}{l}\text { Maximum water level } \\
\text { for differential surge } \\
\text { tank } \\
(\mathrm{m})\end{array}$} & \multicolumn{2}{|c|}{$\begin{array}{l}\text { Minimum water level } \\
\text { for differential surge } \\
\text { tank } \\
(\mathrm{m})\end{array}$} \\
\hline & & $\begin{array}{l}\text { alculated } \\
\text { value }\end{array}$ & & & & & & & & \\
\hline $7^{\#}$ unit & 39.6 & & & & 0.7 & & \multirow{2}{*}{1684.30} & \multirow{2}{*}{1681.31} & \multirow{2}{*}{1605.56} & \multirow{2}{*}{1604.46} \\
\hline $8^{\#}$ unit & 39.1 & 38.9 & 367.50 & 366.33 & 1.48 & -1.79 & & & & \\
\hline
\end{tabular}

Table 3. The primary frequency regulation test conditions of JPII Hydropower Station

\begin{tabular}{|c|c|c|c|c|c|}
\hline Operational mode & $\begin{array}{c}\text { Test } \\
\text { conditions }\end{array}$ & $\begin{array}{l}\text { Upper reservoir } \\
\text { water level (m) }\end{array}$ & $\begin{array}{l}\text { Lower reservoir } \\
\text { water level (m) }\end{array}$ & $\begin{array}{l}\text { Frequency step } \\
\text { signal }(\mathrm{Hz})\end{array}$ & $\begin{array}{l}\text { Initial active power } \\
\text { (MW) }\end{array}$ \\
\hline \multirow{2}{*}{$\begin{array}{l}\text { Frequency difference } \\
\text { opening mode }\end{array}$} & YK1 & \multirow{4}{*}{1639.13} & \multirow{4}{*}{1332.3} & +0.20 & 476 \\
\hline & YK2 & & & -0.20 & 477 \\
\hline \multirow{2}{*}{$\begin{array}{l}\text { Frequency difference } \\
\text { power mode }\end{array}$} & YG1 & & & +0.20 & 457 \\
\hline & YG2 & & & -0.20 & 459 \\
\hline
\end{tabular}

Table 4. The calculated values and test values of primary frequency regulation evaluation index for YK1 and YK2 test conditions

\begin{tabular}{|c|c|c|c|c|c|c|c|c|}
\hline \multirow{2}{*}{$\begin{array}{c}\text { Test } \\
\text { conditions }\end{array}$} & \multicolumn{2}{|c|}{$\begin{array}{l}\text { Load adjustment } \\
\text { amplitude }(\%)\end{array}$} & \multicolumn{2}{|c|}{$\begin{array}{l}\text { Load response lag time } \\
\text { (s) }\end{array}$} & \multicolumn{2}{|c|}{$\begin{array}{l}\text { Time when load adjustment } \\
\text { range reaches } 90 \%(\mathrm{~s})\end{array}$} & \multicolumn{2}{|c|}{$\begin{array}{c}\text { Load adjustment } \\
\text { stabilization time (s) }\end{array}$} \\
\hline & $\begin{array}{l}\text { Test } \\
\text { value }\end{array}$ & $\begin{array}{l}\text { Calculated } \\
\text { value }\end{array}$ & $\begin{array}{c}\text { Test } \\
\text { value }\end{array}$ & $\begin{array}{l}\text { Calculated } \\
\text { value }\end{array}$ & Test value & $\begin{array}{l}\text { Calculated } \\
\text { value }\end{array}$ & Test value & $\begin{array}{l}\text { Calculated } \\
\text { value }\end{array}$ \\
\hline YK1 & -9.3 & -9.7 & 1.8 & 1.7 & 11 & 10.7 & 23 & 21.3 \\
\hline YK2 & 8.8 & 9.0 & 2.3 & 2.1 & 9.3 & 9.7 & 22 & 20.4 \\
\hline
\end{tabular}

\section{Comparative analysis of test and simulation for primary frequency regula- tion}

\subsection{Test conditions}

On the basis of rated frequency of $50 \mathrm{~Hz}, \pm 0.20 \mathrm{~Hz}$ frequency step signal is applied to the grid side to test the response behaviour of primary frequency regulation of the unit. The primary frequency regulation test conditions of 1\# unit for JPII Hydropower Station are shown in Table 3, in which the microcomputer-governor paramet-ers in frequency difference opening mode: $\mathrm{bt}=0.111, \mathrm{Td}=1.125$ $\mathrm{s}, \mathrm{Tn}=0 \mathrm{~s}, \mathrm{Ef}=0.05 \mathrm{~Hz}, \mathrm{bp}=0.04$; the microcom-putergovernor parameters in frequency difference power mode: $\mathrm{bt}=1, \mathrm{Td}=0.385 \mathrm{~s}, \mathrm{Tn}=0 \mathrm{~s}, \mathrm{Ef}=0.05 \mathrm{~Hz}, \mathrm{bp}=0.04$.

\subsection{Frequency difference opening mode}

According to YK1 and YK2 test conditions, using the simulation model of the super-long and large water diversion and power generation system shown in Figure 1, the simulation calculation for primary frequency regulation of $1^{\#}$ unit in frequency difference opening mode is carried out. The comparison between the calculated values of primary frequency regulation evaluation index with the test values is shown in Table 4 . Figure 8 and 9 show the dynamic response comparison curves of primary frequency generation for YK1 and YK2 test conditions.

It can be seen from Figures 8 and 9 that the calculated dynamic response curves of guide vane opening and active power are basically consistent with the test curves, and with the increase or decrease of grid frequency, the guide vane opening and output of Francis turbine can respond to the change of grid frequency quickly and accurately by the microcomputer-governor. In addition, it can be seen from Table 4 that calculated values of the load adjustment amplitude, load response lag time, time when load adjustment range reaches $90 \%$ and load adjustment stabilization time are basically the same as the test values, and the relative values of maximum deviation are only 4.3\%(YK1), 8.69\%(YK2), 4.30\%(YK2) and 7.39\%(YK1) respectively. In view of this, it can be seen that the simulation model of hydraulic transient process established in this paper can accurately reflect the dynamic response characteristics of primary frequency regulation in frequency difference opening mode.
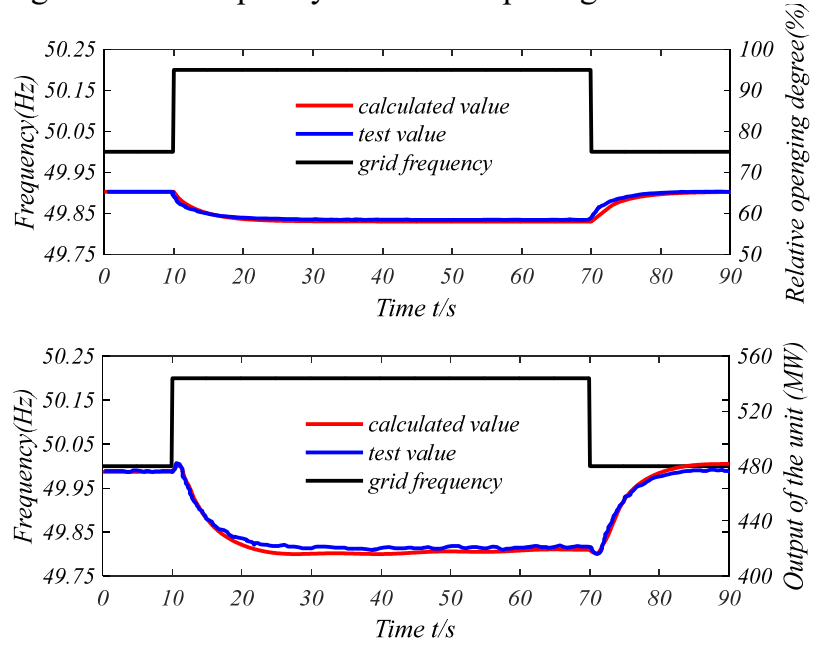

Figure 8. Dynamic response comparison curve of primary frequency generation for YK1 test condition 
Tab.5.The calculated values and test values of primary frequency regulation evaluation index for YG1 and YG2 test conditions

\begin{tabular}{|c|c|c|c|c|c|c|c|c|}
\hline \multirow{2}{*}{$\begin{array}{c}\text { Test } \\
\text { conditions }\end{array}$} & \multicolumn{2}{|c|}{$\begin{array}{c}\text { Load adjustment } \\
\text { amplitude (\%) }\end{array}$} & \multicolumn{2}{c|}{$\begin{array}{c}\text { Load response lag time } \\
\text { (s) }\end{array}$} & $\begin{array}{c}\text { Time when load adjustment } \\
\text { range reaches 90\% (s) }\end{array}$ & \multicolumn{2}{c|}{$\begin{array}{c}\text { Load adjustment } \\
\text { stabilization time (s) }\end{array}$} \\
\cline { 2 - 10 } & $\begin{array}{c}\text { Test } \\
\text { value }\end{array}$ & $\begin{array}{c}\text { Calculated } \\
\text { value }\end{array}$ & $\begin{array}{c}\text { Test } \\
\text { value }\end{array}$ & $\begin{array}{c}\text { Calculated } \\
\text { value }\end{array}$ & Test value & $\begin{array}{c}\text { Calculated } \\
\text { value }\end{array}$ & $\begin{array}{c}\text { Test value } \\
\text { Calculated } \\
\text { value }\end{array}$ \\
\hline YG1 & -7.8 & -7.3 & 2.1 & 1.95 & 10 & 9.5 & 23 & 21.75 \\
\hline YG2 & 8.2 & 7.5 & 2.1 & 2 & 10 & 10.8 & 23 & 22.5 \\
\hline
\end{tabular}
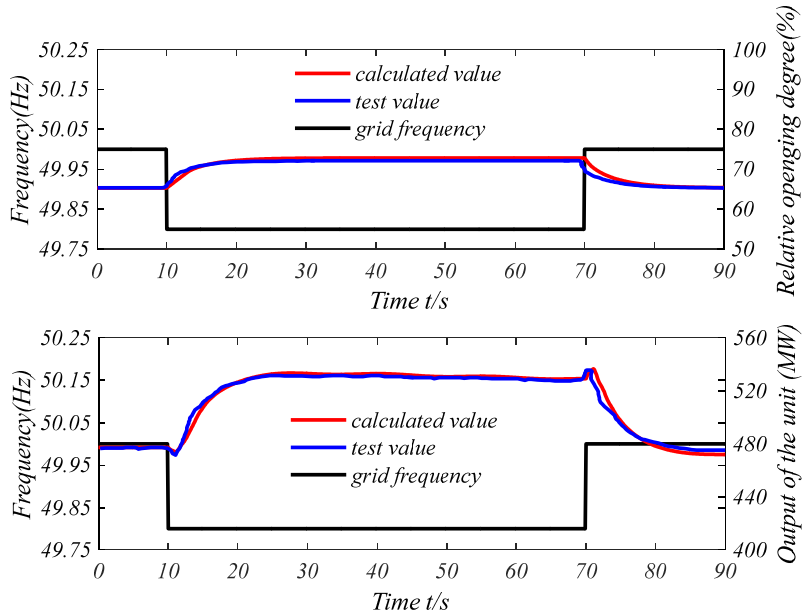

Figure 9. Dynamic response comparison curve of primary frequency generation for YK2 test condition

\subsection{Frequency difference power mode}

According to YG1 and YG2 test conditions, using the simulation model of the super-long and large water diversion and power generation system shown in Figure 1, the simulation calculation for primary frequency regulation of $1^{\#}$ unit in frequency difference power mode is carried out. The comparison between the calculated values of primary frequency regulation evaluation index with the test values is shown in Table 5. Figure 10 and 11 show the dynamic response comparison curves of primary frequency generation for YG1 and YG2 test conditions.

It can be seen from Figures 10 and 11 that the calculated dynamic response curves of guide vane opening and active power under YG1 test condition are basically consistent with the test curves, while the calculated dynamic response curves of guide vane opening and active power under YG2 test condition are slightly different from the test curves. The main reason is that there are some differences between the unit flow and unit torque characteristic data of Francis turbine HYSIM simulation module with the real data, which leads to the deviation between the relationship curve between guide vane opening and output of simulation model with the real situation under some test conditions. In addition, it can be seen from Table 5 that calculated values of the load adjustment amplitude, load response lag time, time when load adjustment range reaches $90 \%$ and load adjustment stabilization time are basically the same as the test values, and the relative values of maximum deviation are 8.5\%(YG2), 7.14\%(YG1), 8.0\%(YG2) and 5.43\% (YG1) respectively. In view of this, it can be seen that the simulation model of hydraulic transient process established in this paper can accurately reflect the dynamic response characteristics of primary frequency regulation in frequency difference power mode.
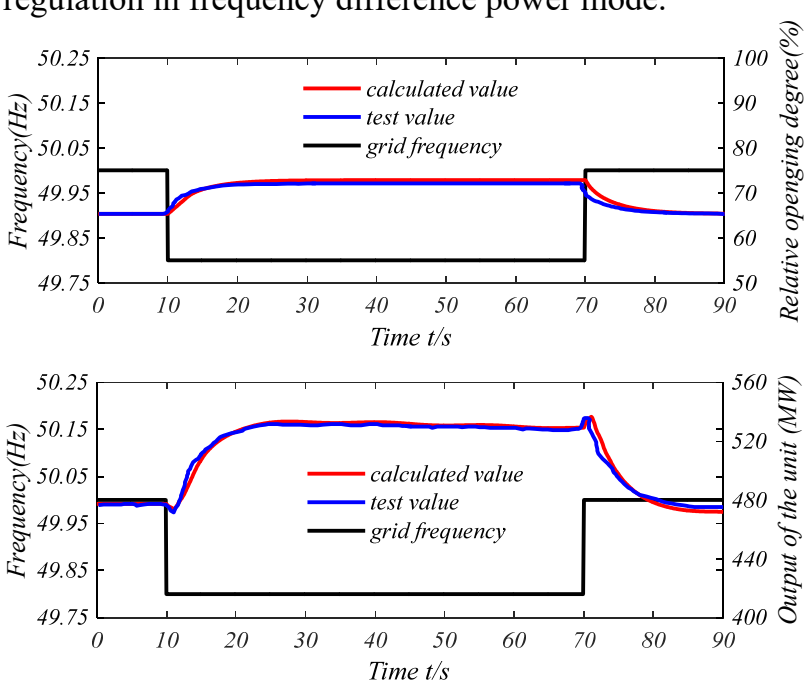

Figure 10. Dynamic response comparison curve of primary frequency generation for YG1 test condition
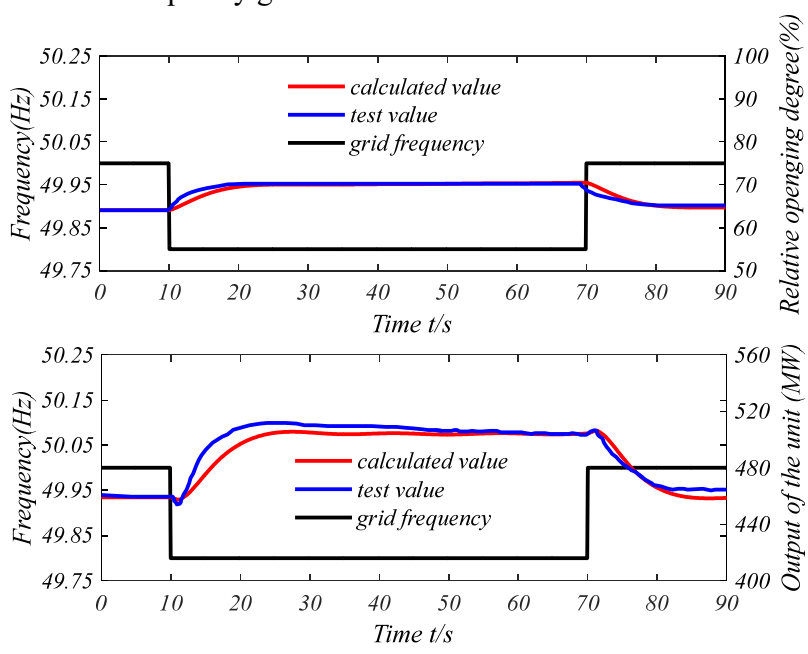

Figure 11. Dynamic response comparison curve of primary frequency generation for $\mathrm{YG} 2$ test condition

\section{Conclusion}

In this paper, using the user-defined modelling function provided by HYSIM software, a complete hydraulic transition process simulation model for super-long and large water diversion and power generation system is built. Based on the simulation model, the correction method of the unit torque curve for the zero opening of Francis turbine is put forward. According to the comparison of calculated and test values, the effectiven-ess of the above method is verified. At the same time, two typical hydraulic transient process test conditions are simulated and analysed, such as double load rejection andprimary 
frequency regulation, and the calculated values are compared with the test values. The comparison results show that the established simulation model can accurately describe the dynamic response characteristics of the superlong and large-capacity hydropower system, thus providing a reliable simulation platform for rechecking the extreme control conditions of the super-long and largecapacity hydropower system and discussing the long-term stable operation mechanism.

\section{References}

1. Wylie, E. B. and Streeter,V.L. "Fluid Transient", McGraw-Hill International Book Company, New York, 1978.

2. Fan Honggang. Study on transient flow calculation of complex hydraulic machinery system [D]. Beijing: Tsinghua University, 2003.

3. Wu Shiyong, Wang Ge. Challenge Issues in construction and project of large scale and deep buried tunnel group of JP II hydropower station [J]. Chinese Journal of Rock Mechanics and Engineering, 2010, 29(11):2161-2171.

4. Chen Xiangrong, Fan Ling, Ju Xiaoming. Hydraulic research and design optimization of the diversion system at JP II hydropower station [J]. Dam \& Safety, 2007, (3): 1-15.

5. Kong Qingrong, Zhang Yongliang, Jiang Chunbo. Study on the Hydraulic Characteristics of JP II Hydropower Station with Long Diversion Tunnel [J].Water Power, 2009, 35(3):32-34, 37.

6. Wu Shiyong, Zhou Jifang, Shen Manbin. Study on check computation of complicated hydraulic transients in super-long water diversion and power generation system of JP II hydropower station [J].Journal of Hydroelectric Engineering, 2015, 34(1):107-116.

7. Cao Chunjian, Fang Jie, Hung Jingqian, Wang Delou. Modelling and dynamic performance analysis on hydraulic mechanical electrical system in hydropower station [J]. Journal of Yangtze River Scientific Research Institute. 2018, 35(8):132-138.

8. Li Gaohui, Wang Delou, Liu ziqiao. Development of hydraulic transition process simulation software and its application in pumped storage power station [J]. Selected Works of Pumped Storage Power Station Construction, 2017, 378-383. 